\title{
A subset of mucosa-associated Escherichia coli isolates from patients with colon cancer, but not Crohn's disease, share pathogenicity islands with urinary pathogenic E. coli
}

\author{
Christina Bronowski, ${ }^{1}$ Shirley L. Smith, ${ }^{1,2}$ Kyoko Yokota, ${ }^{1}$ John E. Corkill, ${ }^{1}$ \\ Helen M. Martin, ${ }^{2}$ Barry J. Campbell, ${ }^{2}$ Jonathan M. Rhodes, ${ }^{2}$ \\ C. Anthony Hart $^{1}$ and Craig Winstanley ${ }^{1}$ \\ ${ }^{1}$ Division of Medical Microbiology, School of Infection and Host Defence, University of Liverpool, \\ Daulby Street, Liverpool L69 3GA, UK \\ ${ }^{2}$ Division of Gastroenterology, School of Clinical Science, University of Liverpool, Crown Street, \\ Liverpool L69 3BX, UK
}

\begin{abstract}
Adherent and invasive mucosa-associated Escherichia coli have been implicated in the pathogenesis of colon cancer and inflammatory bowel diseases. It has been reported that such isolates share features of extraintestinal E. coli (ExPEC) and particularly uropathogenic E. coli (UPEC). We used suppression subtractive hybridization (SSH) to subtract the genome of $E$. coli $\mathrm{K}-12$ from that of a colon cancer mucosal $E$. coli isolate. Of the subtracted sequences, $53 \%$ were present in the genomes of one or more of three sequenced UPEC strains but absent from the genome of an enterohaemorrhagic E. coli (EHEC) strain. Of the subtracted sequences, $80 \%$ matched at least one UPEC genome, whereas only $4 \%$ were absent from the UPEC genomes but present in the genome of the EHEC strain. A further genomic subtraction against the UPEC strain 536 enriched for sequences matching mobile genetic elements, other ExPEC strains, and other UPEC strains or commensals, rather than strains associated with gastrointestinal disease. We analysed the distribution of selected subtracted sequences and UPEC-associated pathogenicity islands (PAls) amongst a panel of mucosa-associated $E$. coli isolated from colonoscopic biopsies of patients with colon cancer, patients with Crohn's disease and controls. This enabled us to identify a group of isolates from colon cancer (30-40\%) carrying multiple genes previously categorized as UPEC-specific and implicated in virulence.
\end{abstract}

Received 10 September 2007

Revised 17 October 2007

Accepted 2 November 2007

\section{INTRODUCTION}

There is increasing recognition that mucosa-associated bacteria may play an important role in the pathogenesis of colon cancer (Mager, 2006) and inflammatory bowel diseases (IBDs), including Crohn's disease. Several independent groups have identified mucosa-associated Escherichia coli in Crohn's disease (Martin et al., 2004; Darfeuille-Michaud et al., 1998; Swidsinski et al., 2002; Ryan et al., 2004; Mylonaki et al., 2005; Kotlowski et al.,

Abbreviations: APEC, avian pathogenic E. coli; CNF1, cytotoxic necrotizing factor 1; EHEC, enterohaemorrhagic E. coli; ExPEC, extraintestinal E. coli; IBD, inflammatory bowel disease; PAl, pathogenicity island; SSH, suppression subtractive hybridization; UPEC, uropathogenic E. coli.

Supplementary tables showing the $E$. coli isolates used in this study and distribution of sequences according to PCR assays, the oligonucleotide primers used for PCR amplification, and the percentage distribution of PAls amongst $E$. coli collections are available with the online version of this paper.
2007). Immunohistochemical studies have shown E. coli antigens within tissue macrophages in Crohn's disease tissue (Liu et al., 1995), and E. coli DNA can be isolated from the majority of Crohn's disease granulomas in tissue sections (Ryan et al., 2004). Similarly, in a prospective study of patients screened for colorectal cancer, intracellular bacteria, notably E. coli, were isolated from both tumour and distant histologically normal mucosa (Swidsinski et al., 1998).

In a previous study, we confirmed that Crohn's disease and colon cancer isolates of E. coli, particularly those lying beneath the colonic mucous layer, were more likely to adhere to and invade epithelial cell lines, and we showed that this property correlated well with their ability to agglutinate human red blood cells, regardless of blood group (Martin et al., 2004). In both Crohn's disease and colon cancer, we (Martin et al., 2004) and others (Swidsinski et al., 1998) have found mucosa-associated $E$. coli that resisted gentamicin treatment of the mucosal 
samples and were therefore presumed to be intracellular. It has been demonstrated that Crohn's disease-associated $E$. coli adhere to and invade epithelial cell lines in vitro (Darfeuille-Michaud et al., 2004; Martin et al., 2004) and replicate inside macrophage phagolysosomes (Bringer et al., 2006), with resulting giant cell formation (Meconi et al., 2007). It has been reported (Kotlowski et al., 2007) that these adherent and invasive E. coli (AIEC) belong to phylogenetic groups B2 and D (Clermont et al., 2000), typical of extraintestinal pathogenic E. coli (ExPEC), and that they exhibit a diffusely adherent pattern of adherence with Hep-2 cells, thus having many of the features of uropathogenic E. coli (UPEC). Like others, we have also shown that they lack the pathogenicity genes associated with $E$. coli that are typically pathogenic in the gut (Martin et al., 2004). Recently, it has been shown that AIEC of phylogenetic groups B2 and D can cause granulomatous colitis in boxer dogs (Simpson et al., 2006).

Thus far, genetic characterization of E. coli strains that occupy the submucosal niches in colon cancer and Crohn's disease has been very limited. Some progress has been made with the identification of genes responsible for adherence to and invasion of epithelial cells, but these studies have only been conducted in one ileal isolate from Crohn's disease, LF82 (Barnich et al., 2004; Rolhion et al., 2005, 2007).

In this study we describe the use of suppression subtractive hybridization ( $\mathrm{SSH}$ ) to characterize the genomic content of a mucosal E. coli colon cancer isolate and further analyse the distribution of subtracted sequences and UPECassociated pathogenicity islands (PAIs) amongst a panel of mucosa-associated E. coli isolated from colonoscopic biopsies of patients with Crohn's disease and colon cancer, and of controls (patients with irritable bowel syndrome and sporadic polyps).

\section{METHODS}

Bacterial strains used in this study. Most of the mucosal isolates of E. coli used in this study (Supplementary Table S1) were described in the study of Martin et al. (2004). The bacteria were obtained after the overlying mucous layer had been removed by DTT treatment from biopsy samples taken from the sigmoid colon (Martin et al., 2004). The ileal isolate E. coli LF82 was a gift from Dr DarfeuilleMichaud, Laboratoire de Bacteriologie, Université d'Auvergne, Clermont-Ferrand, France. The K-12 derivative E. coli JM109 was used to obtain driver DNA for subtractive hybridization. The UPEC strains E. coli $\mathrm{J} 96$ and 536 (gift of Eva Moreno Pujol, Hospital Universitari Vall d'Hebron, Barcelona) were used as controls in PCR assays and, in the case of strain 536, for further subtraction work. All bacteria were maintained by growth on nutrient agar at $37{ }^{\circ} \mathrm{C}$.

Construction and screening of subtraction libraries. Genomic DNA was isolated from E. coli strains using the Wizard Genomic DNA Purification kit (Promega). SSH was carried out using the Clontech PCR-Select Bacterial Genome Subtraction kit as recommended by the supplier. In both hybridizations, DNA from E. coli HM229 was used as tester. DNA from E. coli strains JM109 and 536 was used as the driver in the first and second hybridizations, respectively. All DNAs were digested with RsaI. PCR amplicons obtained following SSH were cloned into pGEM-T (Invitrogen). The subtraction libraries of RsaI fragments thus constructed were screened by sequencing of plasmid DNA extracted from individual clones using M13 forward and reverse vector primers (Cogenics Lark). In order to identify genuinely subtracted sequences, BLASTN searches targeting the genomes of E. coli K-12 and 536 were conducted. Sequences sharing $>90 \%$ identity with the driver genome were omitted from further study. Sequences sharing $<90 \%$ identity with the genome of the relevant driver strain were further analysed using BLASTN and BLASTX searches of the general database. Similar BLASTN searches were used to determine the presence or absence of SSH sequences from the genomes of the UPEC strains CFT073 (Welch et al., 2002), 536 (Brzuszkiewicz et al., 2006) and UTI89 (Chen et al., 2006), and the enterohaemorrhagic E. coli (EHEC) strain EDL933 (Perna et al., 2001). All searches were done using the site http://www.ncbi.nlm.nih.gov.

PCR amplification screening of strains. Oligonucleotide primers (Sigma-Genosys) for PCR amplifications are listed in Supplementary Table S2 along with the annealing temperatures used. DNA for PCR amplification was prepared by boiling a suspension of a few colonies in $5 \% 200 \mu \mathrm{l}$ Chelex-100 (Bio-Rad) for $5 \mathrm{~min}$. After centrifugation, the top $150 \mu \mathrm{l}$ was removed and stored at $-20{ }^{\circ} \mathrm{C}$. For PCR amplification, typically, $1 \mu \mathrm{l}$ DNA was used directly in $25 \mu \mathrm{l}$ volumes containing $1.25 \mathrm{U}$ Taq DNA polymerase (Promega), $1 \times$ TaqMaster (Helena BioSciences), $300 \mathrm{nM}$ each primer, $1 \times$ Taq buffer, $2.5 \mathrm{mM}$ $\mathrm{MgCl}_{2}$ and $100 \mu \mathrm{M}$ nucleotides (dATP, dCTP, dGTP, dTTP). Amplifications were carried out in an Eppendorf MasterCycler thermal cycler for 30 cycles consisting of $95{ }^{\circ} \mathrm{C}$ ( $\left.1 \mathrm{~min}\right)$, annealing temperature $(1 \mathrm{~min})$ and $72{ }^{\circ} \mathrm{C}(2 \mathrm{~min})$, with an additional extension time at $72{ }^{\circ} \mathrm{C}(10 \mathrm{~min})$ following completion of the 30 cycles.

PCR assays for UPEC-specific PAIs have been described elsewhere (Sabaté et al., 2006; Johnson \& Stell, 2000). In this study we used an amended version of the multiplex PCR assays described by Sabate et al. (2006), whereby multiplex PCR B was split into two separate PCR assays consisting of assays for (1) PAI $\mathrm{II}_{\mathrm{J} 96}$ and PAI $\mathrm{I}_{536}$ and (2) PAI $\mathrm{II}_{536}$, PAI I $\mathrm{I}_{\text {CFT073 }}$ and PAI $\mathrm{I}_{\text {J96. }}$. Multiplex PCR A was used to assay for PAI III 536, PAI IV 536 and PAI II $\mathrm{CFT}_{073}$. Amplicon sizes and annealing temperatures are indicated in Supplementary Table S2. For the PAI II $\mathrm{I96}_{96}$ and PAI $I_{536}$ PCR assays, the extension time was increased to $3 \mathrm{~min}$.

Oligonucleotide primers used in PCR assays for PAI VI $\mathrm{V}_{536}$ were designed from SSH sequences obtained in this study. PCR assays for 229-4 and ECP1966 were multiplexed together. Phylogenetic groups were determined using assays published elsewhere (Clermont et al., 2000).

The SSH sequence 229-7 was extended by inverse PCR amplification. Genomic DNA from E. coli HM229 was digested with Sall, ligated using T4 DNA ligase and subjected to PCR amplification using the primers 229-7up ( $5^{\prime}$-TGCGCATGATTACCAGAC-3') and 229-7dn $\left(5^{\prime}\right.$-CGGTTCCTGATGTGTGCTA-3'). The resulting amplicon was sequenced using the same oligonucleotides as primers (Cogenics Lark). Further amplification and sequencing using the primers $5^{\prime}$ GGGCGATTTTTAGAAAGG-3' and 5'-TGCGCGTCATCAGCTTTC$3^{\prime}$ was used to fill in the remaining gap and enable a complete ORF to be obtained.

\section{RESULTS}

\section{Identification of sequences present in the genome of colon cancer isolate $E$. coli HM229 but absent from the genome of $E$. coli JM109}

The colon cancer isolate HM229 was chosen for closer analysis as one of only three mucosal isolates from our 
previous study that carry the $c n f 1$ gene. In addition, it has haemagglutinating activity against neuraminidase-treated group O red blood cells, adheres to and invades the I407 intestinal cell line and adheres to the HT29 intestinal cell line (Martin et al., 2004).

The sequences from a total of $116 \mathrm{SSH}$ clones were obtained. Of the sequences, $85(77 \%)$ were genuinely subtracted from the genome of E. coli K-12, but 10 were repeated, leaving an output of 75 different SSH sequences. Of these, only one gave no significant match when used in a BLASTX search of the database. A summary of all SSH sequences obtained, organized according to their putative function by BLASTX match, is shown in Table 1 .

Of the $75 \mathrm{SSH}$ sequences obtained, 20 (27\%) gave a best BLASTX match with hypothetical proteins or proteins of unknown function, $15(20 \%)$ matched putative membrane proteins, six $(8 \%)$ matched proteins implicated in adherence or haemagglutination, six $(8 \%)$ matched proteins with putative regulatory functions, 10 (7.5\%) were associated with mobile genetic elements and three (4\%) were $\mathrm{O}$ antigen-related (Table 1). Two of the SSH sequences (229-G3 and 229-C6) matched the known virulence-related proteins HlyD (involved in the transport of haemolysin A) and cytotoxic necrotizing factor 1 (CNF1), respectively. In the vast majority of cases, the BLASTX matches were with sequences that shared high levels of identity with sequences from the genomes of E. coli, Shigella, Yersinia or Salmonella. Notable exceptions to this were SSH sequence $229-\mathrm{H} 3$, sharing only $40 \%$ identity with an $\mathrm{O}$ antigen-related protein of Vibrio cholerae, and SSH sequence 229-7, which matched two adjacent genes from E. coli $\mathrm{O} 157: \mathrm{H7}$, but shared only $63 \%$ BLASTX identity with one of these proteins, a putative adhesin/ invasion-related protein (Table 1).

Using inverse PCR amplification, we extended this sequence to obtain the whole of the putative gene (submitted to GenBank; accession no. EU046568). The predicted 441 aa protein shared $64 \%$ identity with an IHP1-like protein from a Shiga toxin-producing E. coli (AAO83376).

Four of the SSH sequences matched hypothetical proteins encoded by an unpublished putative genomic island (AGI1) of the avian pathogenic E. coli (APEC) strain BEN2908.

Using BLASTN searches, the SSH sequences were screened for their presence in three genome-sequenced UPEC strains (CFT073, 536 and UTI89) and a genome-sequenced EHEC strain (EDL933) (Table 1). Of the SSH sequences, $53 \%$ were present in the genomes of one or more UPEC strains but absent from the EHEC strain. A further $27 \%$ were present in the genomes of one or more UPEC strains and the EHEC strain. Sixteen per cent were absent from all four genomes. Only $4 \%$ of SSH sequences were present in the genome of the EHEC strain but absent from the genomes of all UPEC strains. Amongst the SSH sequences were seven with BLASTX matches to putative proteins encoded by one of the 131 UPEC-specific genes identified by Lloyd et al. (2007).

The SSH sequences included sequences that matched parts of the UPEC strain 536 PAIs PAI I 536 , PAI III ${ }_{536}$, PAI IV ${ }_{536}$, PAI $\mathrm{V}_{536}$ and PAI $\mathrm{VI}_{536}$ (Dobrindt et al., 2002; Brzuszkiewicz et al., 2006; Hochhut et al., 2006) and the UPEC strain CFT073 PAIs PAI I $\mathrm{C}_{\mathrm{CFT} 073}$ (Guyer et al., 1998)

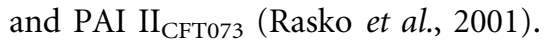

\section{Identification of sequences present in the genome of $E$. coli HM229 but absent from the genome of UPEC strain $\mathbf{5 3 6}$}

Our findings from the initial subtraction suggested that the accessory genome of E. coli HM229 shares more in common with UPEC than with intestinal pathogenic $E$. coli. In an attempt to enrich for genes within the accessory genome that might be specific to bacteria occupying mucosal regions of colon cancer or Crohn's disease, we carried out a second subtraction using the genomesequenced UPEC strain 536 as the driver.

A total of 100 sequences were obtained, of which 62 were genuinely subtracted from the genome of strain E. coli 536 . Four sequences were repeated, leaving a total of 58 different subtracted sequences. Of these $58 \mathrm{SSH}$ sequences, 27 matched neither the UPEC strains UTI89 or CFT073 nor the EHEC strain EDL933 (Table 2). Of these 27, eight had a best BLASTX match against E. coli APEC O1, two had a best BLAST match against $E$. coli $\mathrm{K}-12$, and five mainly $\mathrm{O}$ antigen/capsule-related SSH sequences had a best BLASTX match against other E. coli strains. A further eight SSH sequences matched outside the genus Escherichia. These included a putative SecA-related protein from $V$. cholerae.

\section{Distribution of UPEC PAls amongst isolates from colon cancer and Crohn's disease}

To further assess how closely related our mucosal E. coli isolates were to UPEC E. coli we used published PCR assays to screen a panel of isolates for the major reported UPEC

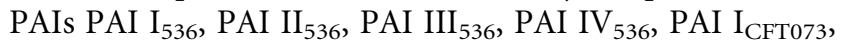
PAI $\mathrm{II}_{\mathrm{CFT} 073}$, PAI I $\mathrm{J}_{96}$ and PAI $\mathrm{II}_{\mathrm{J} 96}$. Furthermore, based on SSH sequences, we designed PCR assays for four genes identified as present within PAI VI ${ }_{536}$. These were designed to target either edge of the PAI [ECP1966 and ECP2038 (229-4)] and the internal ORFs ECP1978 (229-E6) and ECP2007 (229-E4). The results of the PCR assays are presented in Supplementary Table S1 and summarized in Table 3. Notably, there was a group of isolates from colon cancer (30-40\%) that tested PCR-positive for the UPEC PAIs PAI $\mathrm{II}_{\mathrm{J} 96}$, PAI $\mathrm{I}_{536}$, PAI $\mathrm{II}_{536}$ and PAI $\mathrm{II}_{\mathrm{CFT} 073}$. In contrast, one of six control isolates and no Crohn's disease isolates were PCR-positive for these PAIs, with the exception of one Crohn's disease and two control isolates testing PCR-positive for PAI $\mathrm{II}_{\mathrm{CFT} 073}$. The PCR assays for four different sequences from PAI VI ${ }_{536}$ indicated considerable variability in the carriage or nucleotide sequence of 
Table 1. Summary of SSH using the genome of E. coli HM229 as tester and the genome of E. coli JM109 as driver

\begin{tabular}{|c|c|c|c|c|c|c|c|c|c|}
\hline $\begin{array}{l}\text { SSH } \\
\text { sequence }\end{array}$ & $\begin{array}{l}\text { Length } \\
\text { (bp) }\end{array}$ & $\begin{array}{l}\text { Best BLASTX match/comments } \\
\text { [accession no. of best match] }\end{array}$ & $\begin{array}{l}\text { ID } \\
(\%)\end{array}$ & $\begin{array}{l}\text { Length } \\
(\mathbf{a a})^{\star}\end{array}$ & $E$-value & $\begin{array}{l}\text { CFT073 } \\
\text { (UPEC) }\end{array}$ & $\begin{array}{c}\text { UTI89 } \\
\text { (UPEC) }\end{array}$ & $\begin{array}{c}536 \\
(\mathrm{UPEC})\end{array}$ & $\begin{array}{l}\text { EDL } 933 \\
(\text { EHEC) }\end{array}$ \\
\hline & & Bacteriophage-related & & & & & & & \\
\hline $229-10$ & 356 & $\begin{array}{l}\text { Hypothetical protein PhiV10p15 (phage phiV10) } \\
\text { [AAZ95908] }\end{array}$ & 100 & 118 & $2 e-62$ & None & None & None & None \\
\hline $229-21$ & 385 & $\begin{array}{l}\text { Hypothetical protein PhiV10p18 (phage phiV10) } \\
\text { [AAZ95911] }\end{array}$ & 99 & 128 & $3 e-70$ & None & None & None & None \\
\hline 229-D9 & $>225$ & $\begin{array}{l}\text { Hypothetical protein PhiV10p19 (phage phiV10) } \\
\text { [AAZ95912] }\end{array}$ & 93 & 43 & $1 e-15$ & None & None & None & None \\
\hline \multirow[t]{2}{*}{ 229-H7 } & 674 & $\begin{array}{l}\text { Hypothetical protein PhiV10p24 (phage phiV10) } \\
\text { [AAZ95916]; }\end{array}$ & 97 & 85 & $1 e-41$ & None & None & None & None \\
\hline & & Eliminase (phage tail fibre protein) (E. coli K5) [CAA65353] & 100 & 45 & $4 \mathrm{e}-18$ & None & None & None & None \\
\hline $229-6$ & 481 & Bacteriophage P4 integrase (several E. coli) [CAC39282] & 99 & 159 & $3 e-85$ & c4491 & C2634 & None & Z1652 \\
\hline $229-26$ & 594 & Bacteriophage CP4/P4 integrase (several E. coli) [AAL51003] & 97 & 197 & $8 e-108$ & c3556 & C4878 & $\begin{array}{r}\text { ECP2962 } \\
(\text { PAI V) }\end{array}$ & $\mathrm{Z} 4313$ \\
\hline 229-E5 & 487 & Putative phage integrase (Shigella flexneri) [AAP16001] & 100 & 65 & $5 e-33$ & $c 5371$ & C5085 & None & None \\
\hline & & Plasmid/transposon/insertion sequence (IS)-related & & & & & & & \\
\hline 229-G6 & 533 & RepA4, plasmid-associated (several E. coli) [CAA23643] & 98 & 78 & $2 e-31$ & None & None & None & $L 7009$ \\
\hline 229-H9 & 281 & Putative transposase (E. coli O103:H2) [CAI43808] & 96 & 92 & $8 e-46$ & c1219 & None & ECP0279 & None \\
\hline \multirow[t]{2}{*}{ 229-C9 } & 425 & IS629 ORF2 (S. flexneri 2a strain 301 and others) [AAL72366] & 98 & 63 & $2 \mathrm{e}-42$ & $\begin{array}{l}\text { c5178 } \\
(\text { PAI II })\end{array}$ & None & None & Z3295 \\
\hline & & Adhesion/haemagglutination-related & & & & & & & \\
\hline \multirow[t]{2}{*}{$229-7$} & 734 & $\begin{array}{l}\text { Hypothetical protein (E. coli O157: } \mathrm{H} 7 \text { and others) } \\
\text { [BAB33972]; }\end{array}$ & 100 & 37 & $2 \mathrm{e}-13$ & None & $\mathrm{C} 0522$ & None & Z0640 \\
\hline & & $\begin{array}{l}\text { Adhesin/invasin-like protein (E. coli O157:H7 and others) } \\
\text { [BAB33971] }\end{array}$ & 63 & 61 & $6 e-12$ & None & C0521 & None & $Z 0639$ \\
\hline $229-14$ & 582 & $\begin{array}{l}\text { Type } 1 \text { fimbriae regulatory protein FimB (E. coli CFT0730 } \\
\text { and others) [AAN78911] }\end{array}$ & 100 & 191 & $4 e-108$ & c0430 & C0338 & ЕСР0382 & Z0395 \\
\hline 229-H2 & 300 & $\begin{array}{l}\text { PapD P-pilus chaperone (E. coli CFT073 and several others) } \\
\text { [AAN83607] }\end{array}$ & 100 & 99 & $2 e-51$ & $\begin{array}{l}\text { c5185 } \\
(\text { PAI II })\end{array}$ & C4892 & ECP4538 & None \\
\hline $229-29$ & 285 & $\begin{array}{l}\text { Large exoprotein involved in haem utilization or adhesion } \\
\text { (E. coli UTI89, F11 and CFT073) [ABE10349] }\end{array}$ & 97 & 95 & $2 e-44$ & c0345 & C4946 & ECP4580\$ & None \\
\hline 229-B5 & 746 & $\begin{array}{l}\text { Large exoprotein involved in haem utilization or adhesion } \\
\text { (E. coli UTI89 and several others) [ABE10349] }\end{array}$ & 100 & 248 & $3 e-120$ & c0345 & C4946 & ECP4580\$ & None \\
\hline \multirow[t]{2}{*}{ 229-B10 } & 649 & $\begin{array}{l}\text { Putative adhesin/autotransporter, EaeH (E. coli CFT073 and } \\
\text { several others) [AAN78896] }\end{array}$ & 99 & 216 & $3 e-81$ & c0415 & $\mathrm{C} 0321$ & ECP0367 & Z0375 \\
\hline & & Regulation & & & & & & & \\
\hline $229-3$ & 306 & $\begin{array}{l}\text { DNA-binding protein H-NS (E. coli CFT073 and F11) } \\
\text { [AAN80870] }\end{array}$ & 100 & 102 & $4 e-51$ & c2411 & C1434 & $\begin{array}{l}\text { ECP1927 } \\
\text { (PAI IV) }\end{array}$ & Z2013 \\
\hline $229-\mathrm{A} 3$ & 370 & $\begin{array}{l}\text { LemA family protein (E. coli CFT073 and UTI89) } \\
\text { [AAN81785] }\end{array}$ & 100 & 52 & $1 e-23$ & c3337 & C3142 & ECP2756\$ & None \\
\hline 229-H12 & 301 & $\begin{array}{l}\text { Putative signal transduction histidine kinase (E. coli UTI89, } \\
\text { CFT073, F11 and others) [ABE10335] }\end{array}$ & 99 & 100 & $9 e-50$ & $\begin{array}{l}\text { c3564 } \\
(\text { PAI I) }\end{array}$ & C4932 & ECP4563§ & None \\
\hline \multirow[t]{2}{*}{$229-23$} & 745 & Regulatory protein (E. coli CFT073 and others) [AAN83624] & 98 & 78 & $1 \mathrm{e}-38$ & c5202 & None & ECP2977 & None \\
\hline & & $\begin{array}{l}\text { Phosphoglycerate transporter protein PgtP (E. coli CFT073 } \\
\text { and others) [AAN83623] }\end{array}$ & 100 & 67 & $1 e-29$ & c5201 & C2520 & ECP2978 & $Z 3498$ \\
\hline 229-B1 & 616 & $\begin{array}{l}\text { Transcriptional regulator YfjR (E. coli CFT073 and others) } \\
\text { [AAN83000] }\end{array}$ & 99 & 162 & $2 \mathrm{e}-89$ & $\begin{array}{l}\text { c5160 } \\
\text { (PAI II) }\end{array}$ & C4986 & ECP4627\$ & None \\
\hline \multirow[t]{2}{*}{ 229-D6 } & 563 & $\begin{array}{l}\text { Putative transcriptional repressor (E. coli CFT073 and } \\
\text { UTI89) [AAN80226] }\end{array}$ & 100 & 107 & $2 \mathrm{e}-53$ & c1760 & $\mathrm{C} 1562$ & ECP1343 & Z2511 \\
\hline & & Membrane proteins & & & & & & & \\
\hline $229-25$ & 673 & $\begin{array}{l}\text { Outer-membrane protein, RatA homologue (E. coli CFT073) } \\
\text { [AAN81479] }\end{array}$ & 100 & 223 & $4 e-117$ & c3029 & C2828 & ECP2512‡ & None \\
\hline 229-F9 & 631 & $\begin{array}{l}\text { Outer-membrane protein, RatA homologue (E. coli CFT073) } \\
\text { [AAN81479] }\end{array}$ & 100 & 210 & $3 e-111$ & c3029 & C2828 & ECP2512 & : None \\
\hline $229-28$ & 547 & $\begin{array}{l}\text { Putative membrane protein (E. coli UTI89 and F11) } \\
\text { [ABE10586] }\end{array}$ & 100 & 140 & $4 e-66$ & None & P010 & None & None \\
\hline 229-A6 & 485 & Unknown (uncultured bacterium) [AAO59951]; & 96 & 161 & $2 \mathrm{e}-89$ & None & None & None & None \\
\hline
\end{tabular}


Table 1. cont.

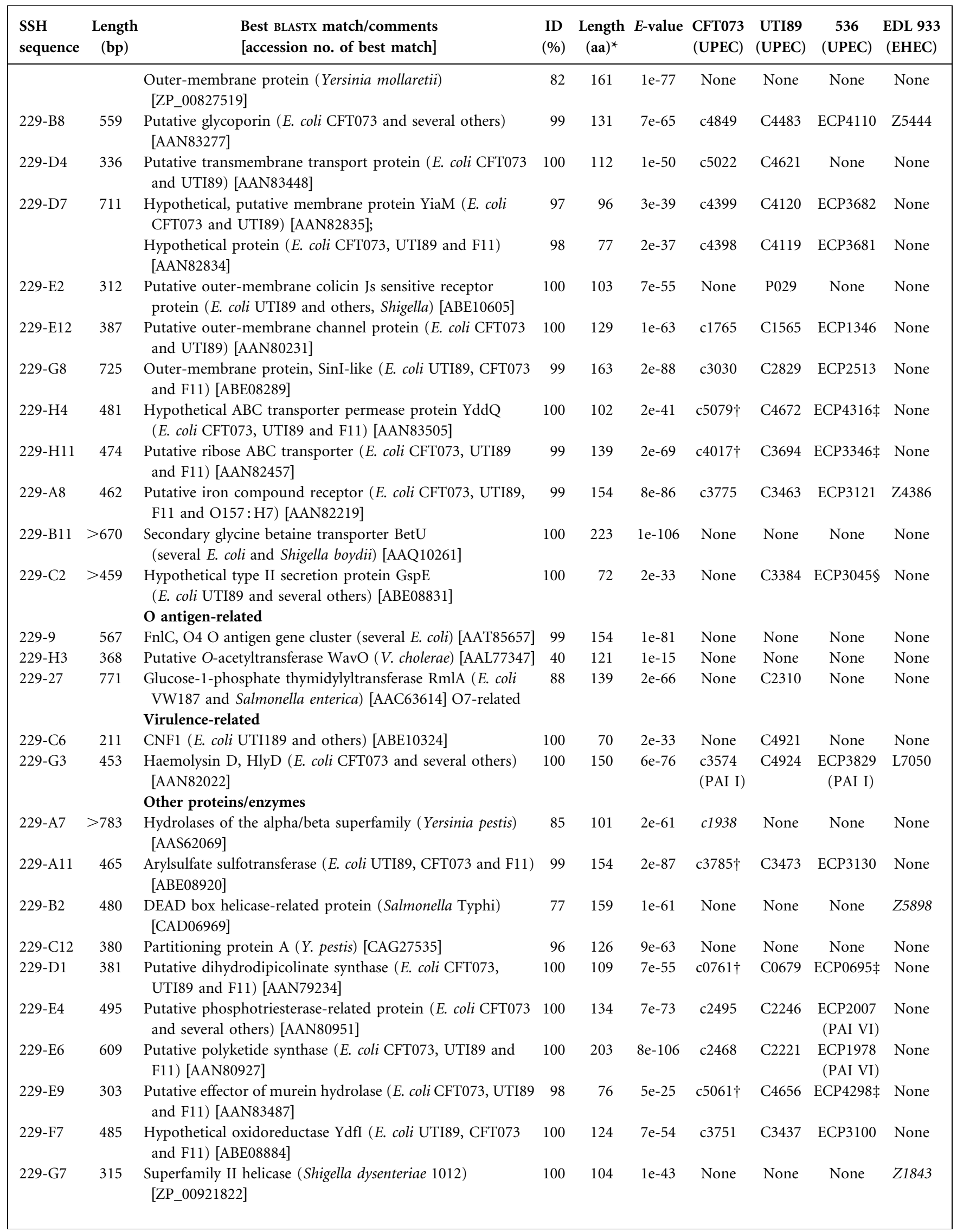


Table 1. cont.

\begin{tabular}{|c|c|c|c|c|c|c|c|c|c|}
\hline $\begin{array}{l}\text { SSH } \\
\text { sequence }\end{array}$ & $\begin{array}{c}\text { Length } \\
\text { (bp) }\end{array}$ & $\begin{array}{l}\text { Best BLASTX match/comments } \\
\text { [accession no. of best match] }\end{array}$ & $\begin{array}{l}\text { ID } \\
(\%)\end{array}$ & $\begin{array}{l}\text { Length } \\
(\text { aa })^{\star}\end{array}$ & $E$-value & $\begin{array}{l}\text { CFT073 } \\
\text { (UPEC) }\end{array}$ & $\begin{array}{l}\text { UTI89 } \\
\text { (UPEC) }\end{array}$ & $\begin{array}{c}536 \\
(\mathrm{UPEC})\end{array}$ & $\begin{array}{c}\text { EDL } 933 \\
(\text { EHEC) }\end{array}$ \\
\hline 229-G11 & 340 & $\begin{array}{l}\text { Carbamate kinase YahI (E. coli CFT073, UTI89 and F11) } \\
\text { [AAN83197] }\end{array}$ & 100 & 113 & $7 e-60$ & c4764† & $\mathrm{C} 4405$ & ECP4034 & $Z 4213$ \\
\hline \multirow[t]{2}{*}{ 229-C10 } & $>456$ & Putative amidase (E. coli CFT073 and UTI89) [AAN80916] & 99 & 152 & $2 e-83$ & c2457 & $\mathrm{C} 2212$ & $\begin{array}{r}\text { ECP1969 } \\
\text { (PAI VI) }\end{array}$ & None \\
\hline & & Hypothetical/unknown proteins & & & & & & & \\
\hline $229-1$ & 576 & $\begin{array}{l}\text { Conserved hypothetical protein } \\
\text { (E. coli CFT073 and others) [AAN83507] } \\
\text { (partial K-12 match over last } 49 \mathrm{bp)}\end{array}$ & 100 & 52 & 1e-19 & c5081† & $\mathrm{C} 4674$ & ECP4318 & : None \\
\hline $229-4$ & 331 & $\begin{array}{l}\text { Conserved hypothetical protein } \\
\text { (E. coli CFT073 and others) [AAN78774] }\end{array}$ & 100 & 85 & $1 \mathrm{e}-40$ & c0286 & C2268 & $\begin{array}{r}\text { ECP2038 } \\
(\text { PAI VI) }\end{array}$ & $\mathrm{Z} 1652$ \\
\hline $229-11$ & 458 & $\begin{array}{l}\text { Hypothetical protein Aec15, AGI-1 } \\
\text { (E. coli BEN2908 and others) [AAQ96709] }\end{array}$ & 100 & 152 & $1 e-83$ & c1888 & $\mathrm{C} 0253$ & ECP0240\$ & $Z 0267$ \\
\hline \multirow[t]{2}{*}{$229-12$} & 384 & $\begin{array}{l}\text { Hypothetical protein Aec7, AGI-1 } \\
\text { (E. coli BEN2908 and UTI89) [AAQ96701]; }\end{array}$ & 100 & 72 & $2 e-32$ & None & $\mathrm{C} 0258$ & ЕСР0248 & None \\
\hline & & $\begin{array}{l}\text { Hypothetical protein Aec8, AGI-1 } \\
\text { (E. coli BEN2908 and UTI89) [AAQ96702] }\end{array}$ & 96 & 32 & $9 \mathrm{e}-10$ & None & C0257 & ЕСР0247\$ & None \\
\hline 229-A10 & 259 & $\begin{array}{l}\text { Hypothetical protein (E. coli CFT073 and UTI89) } \\
\text { [AAN80968] }\end{array}$ & 100 & 41 & $2 \mathrm{e}-17$ & c2513 & $\mathrm{C} 2260$ & $\begin{array}{r}\text { ECP2028 } \\
\text { (PAI VI) }\end{array}$ & None \\
\hline 229-A12 & 755 & $\begin{array}{l}\text { Hypothetical protein SDY_4475 (S. dysenteriae Sd197) } \\
\text { [ABB64351] }\end{array}$ & 93 & 30 & $2 e-7$ & None & None & one & None \\
\hline $229-B 6$ & 551 & $\begin{array}{l}\text { Hypothetical protein (E. coli CFT073 and several others) } \\
\text { [AAN80956] }\end{array}$ & 98 & 50 & $9 e-23$ & c2500 & $\mathrm{C} 2250$ & $\begin{array}{c}\text { ECP2016 } \\
\text { (PAI VI) }\end{array}$ & None \\
\hline 229-B9 & 477 & Hypothetical protein (Sal. Typhi) [AAO70507] & 96 & 32 & $3 e-10$ & None & None & None & None \\
\hline $229-\mathrm{C} 3$ & $>731$ & $\begin{array}{l}\text { Hypothetical protein (E. coli UTI89 and several others) } \\
\text { [ABE08848] }\end{array}$ & 99 & 165 & $3 e-90$ & c3716 & C3401 & ECP3064 & None \\
\hline 229-C4 & 736 & $\begin{array}{l}\text { Hypothetical protein Aec24 (E. coli UTI89 and others) } \\
\text { [ABE05748] }\end{array}$ & 97 & 174 & $4 e-92$ & None & $\mathrm{C} 0245$ & ЕСР0232 & $Z 0257$ \\
\hline 229-D8 & 733 & Hypothetical protein (E. coli F11) [ZP_00726067] & 99 & 156 & $1 e-83$ & c4517 & $\mathrm{C} 4942$ & ECP4576\$ & None \\
\hline 229-E3 & 479 & $\begin{array}{l}\text { Hypothetical protein (E. coli CFT073, UTI89 and O157: H7) } \\
\text { [AAN83171] }\end{array}$ & 100 & 138 & $6 e-81$ & c4738 & C4380 & ECP4011 & Z5334 \\
\hline 229-E11 & 446 & $\begin{array}{l}\text { Uncharacterized conserved protein (E. coli F11) } \\
\text { [ZP_00725602] }\end{array}$ & 87 & 131 & $1 e-61$ & None & None & ECP2816屯 & None \\
\hline $229-F 4$ & 239 & $\begin{array}{l}\text { Hypothetical protein (Aec30) (E. coli UTI89 and F11) } \\
\text { [ABE05742] }\end{array}$ & 100 & 79 & $7 e-36$ & None & C0239 & ЕСР0226 & $Z 0250$ \\
\hline 229-F8 & 478 & $\begin{array}{l}\text { Hypothetical protein YkfF (E. coli CFT073 and UTI89) } \\
\text { [AAN83003] }\end{array}$ & 98 & 77 & $4 e-39$ & c4569 & C4989 & ECP3853§ & $L 7085$ \\
\hline 229-F12 & 275 & Hypothetical protein (E. coli UTI89 and F11) [ABE06867] & 98 & 71 & $8 e-35$ & c1649 & C1385 & ECP1241 & Z1963 \\
\hline $229-\mathrm{G} 10$ & 656 & Hypothetical protein (E. coli CFT073) [AAN82453] & 100 & 116 & $5 e-62$ & c4013 & C3690 & ECP3342 & None \\
\hline 229-H1 & 294 & $\begin{array}{l}\text { Hypothetical protein YiaN (E. coli CFT073 and UTI89) } \\
\text { [AAN82836] }\end{array}$ & 100 & 62 & $3 e-27$ & c4400 & C4121 & ECP3683 & None \\
\hline 229-H6 & 377 & $\begin{array}{l}\text { Hypothetical protein (E. coli CFT073 and UTI89) } \\
\text { [AAN82015] }\end{array}$ & 100 & 125 & $2 \mathrm{e}-71$ & $\begin{array}{l}\text { c3567 } \\
(\text { PAI I })\end{array}$ & C4929 & ECP4560末 & None \\
\hline \multirow[t]{2}{*}{ 229-B4 } & $>222$ & Hypothetical protein (E. coli 536 only) [ABG70017] & 98 & 68 & $9 e-31$ & None & None & $\begin{array}{r}\text { ECP2018 } \\
(\text { PAI VI) }\end{array}$ & None \\
\hline & & No significant hits & & & & & & & \\
\hline 229-G1 & 545 & No significant hits & & & & None & None & None & None \\
\hline
\end{tabular}

${ }^{\star}$ Length refers to the length in amino acid residues of the BLASTX match; †UPEC-specific as defined by Lloyd et al. (2007); UPEC-specific ( $\ddagger$ ) or 536specific $(\$)$ as defined by Brzuszkiewicz et al. (2006). Thus, UPEC-specific indicates present in CFT073 and 536 but absent from two EHEC genomes and K-12; 536-specific indicates absent from all other genome-sequenced E. coli strains at the time of publication. ORFs located within strain CFT073 or strain 536 PAIs are indicated by showing the island in parentheses. Italic type indicates a considerably weaker match than the best BLASTX match; matches $<50 \%$ identity (ID) to the genomes of CFT073, UTI89 or EDL933 were discounted. 
Table 2. Summary of SSH using the genome of $E$. coli HM229 as tester and the genome of E. coli 536 as driver

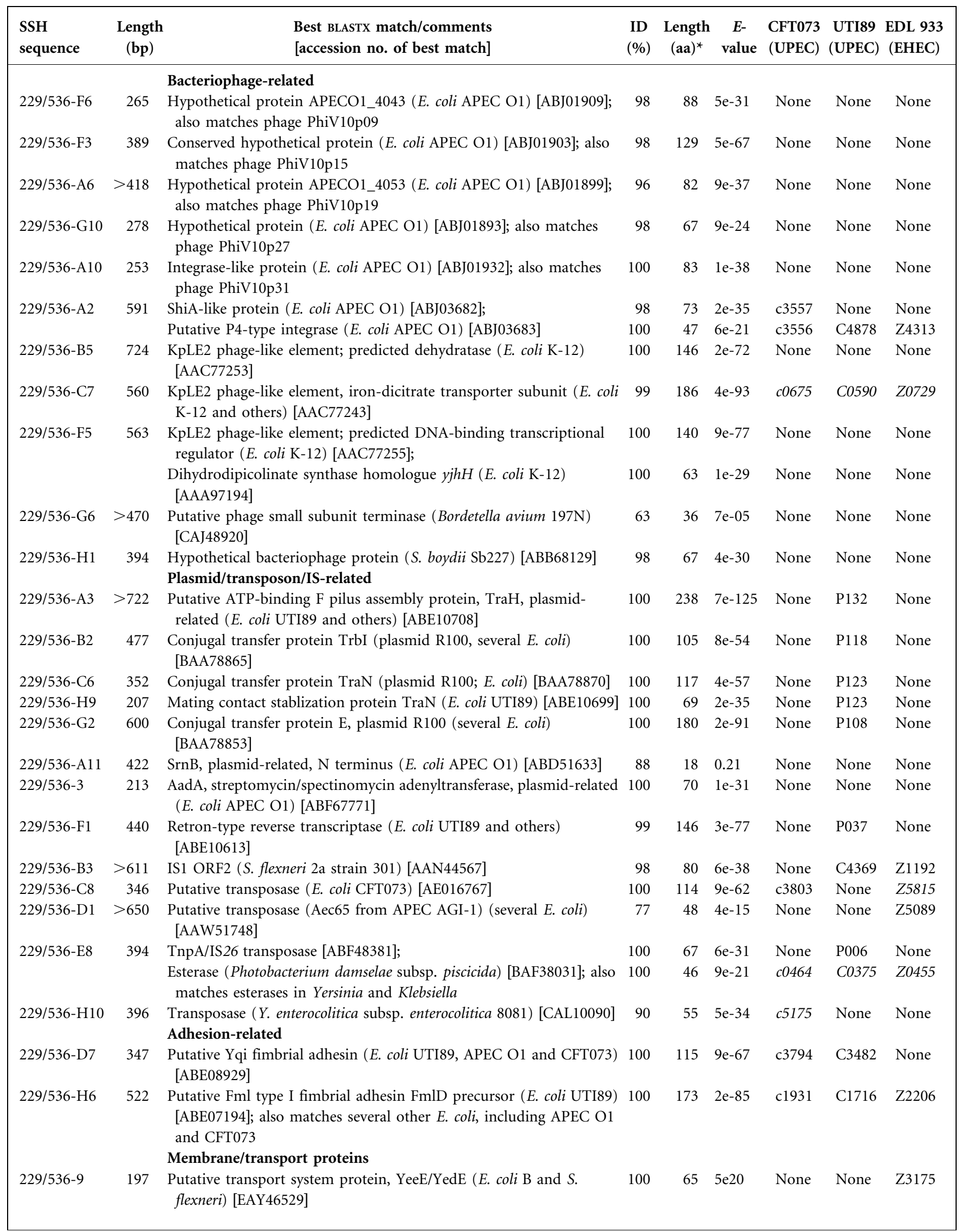


Table 2. cont.

\begin{tabular}{|c|c|c|c|c|c|c|c|c|}
\hline $\begin{array}{l}\text { SSH } \\
\text { sequence }\end{array}$ & $\begin{array}{l}\text { Length } \\
\text { (bp) }\end{array}$ & $\begin{array}{l}\text { Best BLASTX match/comments } \\
\text { [accession no. of best match] }\end{array}$ & $\begin{array}{l}\text { ID } \\
(\%)\end{array}$ & $\begin{array}{l}\text { Length } \\
(\mathbf{a a})^{\star}\end{array}$ & $\begin{array}{c}E- \\
\text { value }\end{array}$ & $\begin{array}{l}\text { CFT073 } \\
\text { (UPEC) }\end{array}$ & $\begin{array}{l}\text { UTI89 } \\
\text { (UPEC) }\end{array}$ & $\begin{array}{c}\text { EDL } 933 \\
(\text { EHEC) }\end{array}$ \\
\hline 229/536-B9 & $>349$ & $\begin{array}{l}\text { Putative outer-membrane protein YieC precursor (E. coli UTI89) } \\
\text { [ABE07231]; also matches E. coli CFT073 and APEC O1 }\end{array}$ & 98 & 115 & $2 e-55$ & c1956 & $\mathrm{C} 1753$ & None \\
\hline $229 / 536-\mathrm{C} 1$ & 277 & EntS/YbdA MFS transporter (E. coli UTI89) [ABE07105] & 95 & 73 & $4 e-32$ & None & C1627 & None \\
\hline 229/536-D5 & 504 & $\begin{array}{l}\text { PTS system, galactitol-specific IIC component (E. coli UTI89) } \\
\text { [ABE09431] }\end{array}$ & 99 & 167 & $9 e-87$ & c4279 & C4002 & Z4877 \\
\hline 229/536-E11 & 189 & Predicted transporter component (several E. coli) [ZP_00713448] & 100 & 63 & $3 e-30$ & None & None & $\mathrm{Z} 3175$ \\
\hline 229/536-H7 & 347 & $\begin{array}{l}\text { SecA-related protein ( } V . \text { cholerae MAK } 757 \text { ) [EAY39281] } \\
\text { O antigen/capsule-related }\end{array}$ & 45 & 111 & $4 \mathrm{e}-24$ & None & None & None \\
\hline 229/536-B4 & 449 & $\begin{array}{l}\text { WbuG, O4 antigen glycosyl transferase family protein (E. coli) } \\
\text { [AAT85652] }\end{array}$ & 100 & 136 & $3 e-74$ & None & None & None \\
\hline 229/536-D4 & 453 & FnlC O antigen biosynthesis protein (several E. coli) [AAT85657] & 100 & 150 & $5 e-80$ & None & None & None \\
\hline 229/536-D2 & 308 & $\begin{array}{l}\text { KpsD, group III capsular polysaccharide transport protein (E. coli } \\
\text { CP9) [AAC38077] }\end{array}$ & 98 & 77 & $7 e-26$ & None & None & None \\
\hline 229/536-H3 & $>652$ & $\begin{array}{l}\text { KpsD, group III capsular polysaccharide transport protein (E. coli } \\
\text { CP9) [AAC38077] }\end{array}$ & 100 & 217 & $6 e-111$ & None & None & None \\
\hline 229/536-H5 & $>720$ & $\begin{array}{l}\text { dTDP-D-glucose-4,6-dehydratase, O antigen or capsule-related } \\
\text { (Aeromonas hydrophila and many other bacteria) [AAM74474] } \\
\text { Virulence-related }\end{array}$ & 91 & 181 & $8 e-81$ & $c 4708$ & C2312 & Z5299 \\
\hline $229 / 536-7$ & 383 & $\begin{array}{l}\text { Hypothetical protein UTI89_C4920 (E. coli UTI89) [ABE10323] } \\
\text { CNF1 (E. coli) [CAK02719] } \\
\text { Other proteins/enzymes }\end{array}$ & $\begin{array}{r}98 \\
100\end{array}$ & $\begin{array}{l}68 \\
36\end{array}$ & $\begin{array}{l}5 e-26 \\
7 e-11\end{array}$ & $\begin{array}{l}\text { None } \\
\text { None }\end{array}$ & $\begin{array}{l}\text { C4920 } \\
\text { C4921 }\end{array}$ & $\begin{array}{l}\text { None } \\
\text { None }\end{array}$ \\
\hline $229 / 536-8$ & 302 & $\begin{array}{l}\text { Phosphoglycerate dehydrogenase (E. coli UTI89 and APEC O1) } \\
\text { [ABE09403] }\end{array}$ & 100 & 100 & $4 e-50$ & None & C3974 & None \\
\hline 229/536-B10 & $>534$ & $\begin{array}{l}\text { Putative propionate CoA-transferase (E. coli CFT073) [AE016770]; } \\
\text { also matches E. coli UTI89 and APEC O1 }\end{array}$ & 99 & 166 & $1 e-93$ & c5024 & $\mathrm{C} 4623$ & None \\
\hline 229/536-B11 & $>432$ & $\begin{array}{l}\text { Putative oxidoreductase (E. coli UTI89) [ABE10028]; also matches E. } \\
\text { coli CFT073 and APEC O1 }\end{array}$ & 100 & 143 & $4 \mathrm{e}-78$ & c5021 & C4620 & None \\
\hline 229/536-E5 & 477 & $\begin{array}{l}\text { Putative oxidoreductase (E. coli UTI89 and others) [ABE10028] } \\
\text { (different from B11) }\end{array}$ & 100 & 159 & $6 e-89$ & c5021 & C4620 & None \\
\hline 229/536-C5 & 388 & $\begin{array}{l}\text { Probable DMSO reductase chain ynfF precursor (E. coli CFT073 and } \\
\text { others) [AE016761] }\end{array}$ & 100 & 111 & $2 e-59$ & c1978 & $\mathrm{C} 1775$ & Z2576 \\
\hline 229/536-D8 & 647 & $\begin{array}{l}\text { N-Acetylneuraminate synthase (Rhodopseudomonas palustris BisA53) } \\
\text { [ABJ08161] }\end{array}$ & 31 & 203 & $2 e-19$ & None & None & None \\
\hline 229/536-D10 & 288 & $\begin{array}{l}\text { Long-chain fatty acid transport protein precursor (E. coli CFT073) } \\
\text { [AE016764] }\end{array}$ & 100 & 95 & $2 e-49$ & c2889 & C2629 & Z3608 \\
\hline 229/536-G7 & $>444$ & $\begin{array}{l}\text { 5-Methylthioribose kinase (Sinorhizobium medicae WSM419) } \\
\text { [ABR64583] }\end{array}$ & 46 & 124 & $2 e-26$ & None & None & None \\
\hline 229/536-G8 & 385 & $\begin{array}{l}\text { DNA methylase M, restriction-modification-related (E. coli UTI89) } \\
\text { [ABE10454]; also matches E. coli APEC O1 and K12 } \\
\text { Hypothetical/unknown proteins }\end{array}$ & 100 & 85 & $3 e-44$ & None & C5051 & None \\
\hline $229 / 536-10$ & 385 & Hypothetical protein APECO1_4055 (E. coli APEC O1) [ABJ01897] & 98 & 78 & $3 e-40$ & None & None & None \\
\hline 229/536-B1 & 615 & $\begin{array}{l}\text { Hypothetical protein YberA_01003280 (Yersinia bercovieri ATCC } \\
\text { 43970) [ZP_00820565] }\end{array}$ & 65 & 205 & $7 e-76$ & None & None & None \\
\hline 229/536-D11 & $>323$ & $\begin{array}{l}\text { Hypothetical protein Bamb_5065 (Burkholderia cepacia AMMD) } \\
\text { [ABI90614] }\end{array}$ & 36 & 87 & $9 e-11$ & None & None & None \\
\hline 229/536-E12 & $>347$ & Hypothetical protein (E. coli W3110) [BAE78334] & 99 & 115 & $1 e-59$ & None & None & None \\
\hline 229/536-G5 & 485 & $\begin{array}{l}\text { Hypothetical protein (uncultured bacterium, and non-E. coli bacteria } \\
\text { including Yersinia) [AAO59951] }\end{array}$ & 96 & 161 & $3 e-89$ & None & None & None \\
\hline 229/536-H8 & 251 & Hypothetical protein, $\mathrm{N}$ terminus (E. coli CFT073) [AE016766] & 93 & 16 & 1.8 & c3653 & None & None \\
\hline 229/536-H11 & $>330$ & $\begin{array}{l}\text { Hypothetical protein (E. coli UTI89) [ABE10538]; also matches E. coli } \\
\text { CFT073 } \\
\text { No significant hits (NSH) }\end{array}$ & 100 & 110 & $5 e-59$ & c3148 & C5138 & None \\
\hline $229 / 536-6$ & 159 & $\mathrm{NSH}$ & & & & None & None & None \\
\hline 229/536-A5 & 226 & NSH & & & & None & None & None \\
\hline 229/536-G4 & $>552$ & $\mathrm{NSH}$ & & & & None & None & None \\
\hline 229/536-H2 & 418 & $\mathrm{NSH}$ & & & & None & None & None \\
\hline
\end{tabular}


Table 2. cont.

${ }^{\star}$ Length refers to the length of the BLASTX match. Italic type indicates a considerably weaker match than the best BLASTX match; matches $<50 \%$ identity (ID) to the genomes of CFT073, UTI89 or EDL933 were discounted.

this island. Whilst some isolates were PCR-positive for all four of the sequences, others were PCR-positive for none, one, two or three of the sequences (Supplementary Table S1). The proportion of isolates that were PCR-positive for all four sequences was greater amongst the colon cancer isolates than either the Crohn's disease isolates or the controls (Table 3).

\section{Distribution of other selected SSH sequences amongst isolates from colon cancer and Crohn's disease}

Using PCR assays we further tested the distribution of three SSH sequences with possible roles in pathogenicity: 229-7, 229-29 and 229-11. The putative adhesion/invasionrelated sequence 229-7 was only identified by PCR assay in the group of colon cancer isolates also associated with the carriage of the UPEC PAIs PAI II ${ }_{596}$, PAI I ${ }_{536}$, PAI $\mathrm{II}_{536}$ and PAI $\mathrm{II}_{\mathrm{CFT073}}$. Apart from one control isolate and one Crohn's disease isolate, the same subset of colon cancer isolates were also the only members of the panel that tested PCR-positive for the putative adhesion/haemagglutinationrelated SSH sequence 229-29. The PCR analysis suggested that the APEC-associated island AGI-1 has a wider distribution (Table 3).

It has been reported previously that the P-fimbriaeassociated papC is present in many of the mucosal isolates (Martin et al., 2004). Since the PCR assays based on the study of Sabaté et al. (2006) were only designed to identify one pap $G$ allele type, we used further PCR assays to identify other pap $G$ allele types. The most common was pap $G$ allele II (Table 3).

\section{DISCUSSION}

The contribution of PAIs to the evolution of bacterial pathogens has been widely acknowledged (Dobrindt et al., 2004; Schmidt \& Hensel, 2004; Gal-Mor \& Finlay, 2006). E. coli is one of the best-studied examples of a bacterial pathogen that exhibits diversity in virulence due to the carriage of specific combinations of virulence genes and PAIs (Kaper et al., 2004). In particular, several groups have sought to identify and characterize UPEC-specific PAIs (Lloyd et al., 2007; Welch et al., 2002; Chen et al., 2006; Oelschlaeger et al., 2002a; Brzuszkiewicz et al., 2006). In the

Table 3. Percentage of isolates from various sources carrying sequences

Abbreviations: CD, Crohn's disease; UC, ulcerative colitis.

\begin{tabular}{|c|c|c|c|c|c|}
\hline \multirow[t]{2}{*}{ Sequence } & \multicolumn{5}{|c|}{ Source } \\
\hline & $\begin{array}{l}\text { Cancer } \\
(n=10)\end{array}$ & CD $(n=8)$ & UC $(n=1)$ & $\begin{array}{c}\text { Control } \\
(n=6)\end{array}$ & $\begin{array}{c}\text { Total } \\
(n=25)\end{array}$ \\
\hline 229-29 (adhesion/haem utilization) & 40 & 13 & 0 & 17 & 24 \\
\hline 229-7 (adhesion/invasion) & 30 & 0 & 0 & 0 & 12 \\
\hline 229-11 (AGI-1) & 60 & 38 & 0 & 50 & 48 \\
\hline ECP1966 (PAI VI $\left.{ }_{536}\right)$ & 40 & 13 & 0 & 33 & 28 \\
\hline 229-E6 (PAI VI $\left.{ }_{536}\right)$ & 40 & 13 & 0 & 33 & 28 \\
\hline 229-E4 (PAI VI $\left.{ }_{536}\right)$ & 80 & 63 & 100 & 67 & 72 \\
\hline $229-4\left(\mathrm{PAI} \mathrm{VI}_{536}\right)$ & 70 & 38 & 100 & 50 & 56 \\
\hline hlyD/cnF1 (PAI II $\left.{ }_{996}\right)$ & 40 & 0 & 0 & 17 & 20 \\
\hline I9/I10 (PAI I I36 $\left._{2}\right)$ & 30 & 0 & 0 & 17 & 16 \\
\hline Orflup/down (PAI II $\left.{ }_{536}\right)$ & 30 & 0 & 0 & 17 & 16 \\
\hline RPAi/RPAf (PAI I CFT073 ) & 90 & 67 & 0 & 50 & 72 \\
\hline sfaI.1/2 (PAI III $\left.{ }_{536}\right)$ & 0 & 0 & 0 & 0 & 0 \\
\hline IRP2FP/RP (PAI IV $\left.{ }_{536}\right)$ & 90 & 67 & 100 & 100 & 88 \\
\hline Cft073Ent1/2 (PAI II $\left.{ }_{\text {CFT073 }}\right)$ & 50 & 13 & 0 & 17 & 32 \\
\hline papGIf/r (PAI I I96 $)$ & 0 & 0 & 0 & 0 & 0 \\
\hline papG allele II & 50 & 50 & 0 & 33 & 44 \\
\hline papG allele III & 10 & 0 & 0 & 17 & 4 \\
\hline papC & 70 & 63 & 0 & 50 & 60 \\
\hline
\end{tabular}


study of Brzuszkiewicz et al. (2006), the 536 islands are described as either 536-specific (for PAI $\mathrm{I}_{536}$ and PAI $\mathrm{V}_{536}$ ) or as part of the 'common ExPEC gene pool' (for PAI II ${ }_{536}$, PAI III $_{536}$, PAI IV 536 and PAI VI I36 $_{53}$ although some genes from PAI $\mathrm{II}_{536}$ and PAI $\mathrm{III}_{536}$ fall into the '536-specific' category).

A simple phylogenetic scheme based on the presence or absence of a few selected genes has been used to demonstrate genetic differences between intestinal E. coli and ExPEC (Clermont et al., 2000). Several studies have noted the predominance of phylogenetic groups $\mathrm{B} 2$ and $\mathrm{D}$ amongst UPEC isolates (Johnson et al., 2005; Houdouin et al., 2006; Sabaté et al., 2006; Bidet et al., 2007) or meningitis isolates (Bidet et al., 2007; Ewers et al., 2007). However, few studies have sought to characterize E. coli isolates associated with IBD or colon cancer. Kotlowski et al. (2007) identified groups B2 and D as being of high prevalence in Crohn's disease, and they also screened Crohn's and ulcerative colitis isolates for the presence of multiple virulence genes, including adhesins. Interestingly, none carried cnfl/hlyA, an observation supported by our study with respect to Crohn's disease isolates.

Nevertheless, we found a group of colon cancer isolates that carried not only the cnf $1 / h l y A$ associated with PAI $\mathrm{II}_{\mathrm{J} 96}$ but also several other UPEC-associated islands. Interestingly, the I9/I10 putative fimbrial chaperone of PAI $\mathrm{I}_{536}$ and the ORF1 (ECP4571) region of PAI $\mathrm{II}_{536}$ match only the genomes of UPEC strains 536 and UTI89 when used to search the database. In addition, the CFT073 ferric enterobactin-transport protein/siderophore of PAI $\mathrm{II}_{\mathrm{CFT} 073}$ matches sequences from only four UPEC strains in the database. Thus, our distribution study indicates the presence amongst the colon cancer isolates of a group of $E$. coli isolates that carry multiple genes previously categorized as UPEC-specific. However, it has been reported that the accessory genome of a commensal $E$. coli strain which is a clinically safe, efficient colonizer of the gut also contains cnfl, hlyA and PAI II ${ }_{536}$ (Hejnova et al., 2005). Those authors suggested that these 'virulence-associated' genes might actually be contributing to fitness or colonization. It is worth noting that although related in the content of their accessory genome, isolates HM213, HM229 and HM334 are different according to typing by PFGE (Martin et al., 2004) and flagellin gene sequence (data not shown).

A closer analysis of the genome of a representative of this group, strain HM229, using SSH against E. coli K-12, indicated that the accessory genome of this strain was much more closely related to the genomes of UPECs than to those of intestinal E. coli. However, some subtracted sequences were not UPEC-associated. Four of the SSH sequences matched the E. coli $\mathrm{O} 157: \mathrm{H} 7$ bacteriophage PhiV10, which has been completely sequenced (GenBank accession no. DQ126339), but for which there is no publication. Three further SSH sequences matched integrases, including one (SSH229-26) that matched a P4-like $\mathrm{PAI}$-associated integrase similar to those implicated in playing an important role in the plasticity of $E$. coli genomes (Hochhut et al., 2006; Manson \& Gilmore, 2006).

Further subtraction against the UPEC strain 536 enriched for sequences matching mobile genetic elements, other ExPEC strains such as APEC O1, and other UPEC strains or commensals, rather than strains associated with gastrointestinal disease. It has been reported elsewhere that the genome sequence of the avian pathogenic E. coli strain $\mathrm{O} 1: \mathrm{K} 1: \mathrm{H} 7$ shares strong similarities with human ExPEC genomes (Johnson et al., 2007). Two SSH sequences matched KpsD, a group 2 capsular polysaccharide production protein from a bacteraemia isolate (CP9). Group 2 capsule operons consist of highly conserved regions (e.g. $k p s D M T E$ ) that encode transport and assembly functions, combined with highly variable typespecific regions that encode the synthesis and/or polymerization of the specific component sugars of the particular polysaccharide (Whitfield \& Roberts, 1999).

Sabaté et al. (2006) compared 100 UPEC and 50 commensal E. coli isolates, according to single PCR assays for each of eight UPEC-associated PAIs. Overall, $93 \%$ of UPEC isolates carried PAIs, compared to $40 \%$ of commensal isolates. However, it is interesting to compare the percentage carriage of individual islands between the isolate sets used in our study and that of Sabaté et al. (2006). The percentage carriage of many PAIs was very similar between isolates from UPEC (Sabaté et al., 2006) and colon cancer (Supplementary Table S3). It is also interesting to note that isolates carrying the same number of PAIs generally carry the same combinations of PAIs. This tendency towards specific combinations of PAIs has been reported before for UPEC and commensal isolates (Sabaté et al., 2006), and is indicative of a stepwise sequential programme of evolution rather than a random acquisition of PAIs.

Based on four PCR assays alone, we found some evidence for variations in PAI $\mathrm{VI}_{536}$ amongst the isolates in our panel. Instability in UPEC PAIs has been demonstrated before (Middendorf et al., 2004). Again, isolates sharing the same number of PCR-positives for the four assays had the same combination of PCR-positives. Thus, even within a single PAI, there is evidence for sequential evolution.

PAI $\mathrm{IV}_{536}$ is the most widely distributed of the islands amongst commensal and UPEC isolates (Sabaté et al., 2006). This island is related to the so-called highpathogenicity island (HPI), which is widespread amongst the Enterobacteriaceae (Schubert et al., 2004).

It has been demonstrated that the ability of UPEC to cause symptomatic infection is enhanced by adhesins, including type 1 and $\mathrm{P}$ fimbriae (Klemm \& Schembri, 2000; Oelschlaeger et al., 2002b). The SSH analysis of strain HM229 identified sequences from both type 1 and $\mathrm{P}$ fimbriae. P fimbriae, encoded by the pap operon, enhance the establishment of bacteriuria, activate the innate immune response (Wullt et al., 2000, 2002; Bergsten et al., 
2004), and are widely distributed in UPEC and APEC (Johnson \& Stell, 2000; Rodriguez-Siek et al., 2005). Binding is mediated by the tip adhesin PapG, which has at least three allelic forms, of which allele II is the most common (Johnson et al., 1998; Johnson \& Stell, 2000). $p a p C$ was widely distributed amongst the mucosal isolates from colon cancer (7/10) and Crohn's disease (4/8), with the relative distributions of the pap $G$ alleles resembling those reported elsewhere for UPEC (Johnson \& Stell, 2000; Houdouin et al., 2006). However, for three papC PCRpositive isolates we did not get a PCR-positive for any of the papG alleles [including the rare pap $G I^{a}$ allele variant (Johnson \& Stell, 2000) (data not shown)], suggesting further allelic variation. An association between pap $G$ allele III and cnf1 has been reported elsewhere for UPEC (Johnson \& Stell, 2000). However, of the three cnf1positive isolates in this study, only one carried papG allele III.

The SSH analysis also identified other putative gene/ protein sequences with predicted roles in adherence, invasion or haemagglutination. The SSH sequence 229-29 shared similarity with large proteins implicated in haem utilization or adhesion in UPEC. The SSH sequence 229-7 carries a YadA-like C-terminal region. YadA is the major adhesin of Yersinia enterocolitica, and is essential for establishing infection by mediating adhesion to host cells and conferring resistance against bactericidal activity. We made a knockout mutant for the full ORF associated with SSH sequence 229-7. However, we could identify no change in either adherence or invasion with $\mathrm{I} 407$ or Caco-2 cell lines, nor could we detect any difference in haemagglutination (data not shown). This may be because these are multifactorial phenotypes. For example, UPEC carry multiple adhesion-related genes, but carriage of individual adhesion-related genes, such as papC, can be well below $100 \%$ (Johnson \& Stell, 2000; Rodriguez-Siek et al., 2005; Houdouin et al., 2006).

PCR screening of Crohn's disease and cancer E. coli isolates for the presence of sequences 229-7 and 229-29 suggested a distribution very similar to that of cnfl (Supplementary Table S1). In particular, the colon cancer isolates HM213, HM229 and HM334 carry cnf1, 229-7 and 229-29. The exotoxin CNF1 is an acknowledged virulence factor of UPEC but its prevalence has been reported as $16-27.5 \%$ of UPEC isolates (Johnson \& Stell, 2000; Rodriguez-Siek et al., 2005). Hence, the carriage rates for our colon cancer isolates for this UPEC-associated virulence factor are very similar to the reported figures for UPEC isolates. In contrast, either none or only one of the Crohn's disease isolates carried many of the pathogenicity-related genes.

The possible role of mucosally adherent $E$. coli in colon cancer pathogenesis is currently speculative, but there is growing interest in the possible role of inflammation (Rhodes \& Campbell, 2002), and perhaps particularly in $\mathrm{NF} \kappa \mathrm{B}$ activation (Greten et al., 2004), in colon cancer. Bacterial adhesion, perhaps to dysplastic mucosa lacking an overlying mucus coat, has the potential to induce epithelial cell changes that could promote cancer development (Hope et al., 2005).

It is clear from our study and others that neither the colon cancer nor the Crohn's disease mucosal E. coli populations are uniform. However, it is possible that a subset of isolates plays an important role in the pathogenicity of these diseases. We identified a subset of colon cancer isolates, not represented amongst the Crohn's disease isolates, that carry multiple UPEC-associated virulence genes. The clinical relevance of this group remains unknown, but the presence of such strains merits further investigation.

\section{ACKNOWLEDGEMENTS}

We would like to acknowledge support from the North West Cancer Research Fund.

We would like to dedicate this paper to the memory of Professor Tony Hart, an inspirational colleague who is sadly missed by us and by many others in the worldwide microbiological community.

\section{REFERENCES}

Barnich, N., Bringer, M. A., Claret, L. \& Darfeuille-Michaud, A. (2004). Involvement of lipoprotein NlpI in the virulence of adherent invasive Escherichia coli strain LF82 isolated from a patient with Crohn's disease. Infect Immun 72, 2484-2493.

Bergsten, G., Samuelsson, M., Wullt, B., Leijonhufvud, I., Fischer, H. \& Svanborg, C. (2004). PapG-dependent adherence breaks mucosal inertia and triggers the innate host response. J Infect Dis 189, 1734-1742.

Bidet, P., Metais, A., Mahjoub-Messai, F., Durand, L., Dehem, M., Aujard, Y., Bingen, E., Nassif, X. \& Bonacorsi, S. (2007). Detection and identification by PCR of a highly virulent phylogenetic subgroup among extraintestinal pathogenic Escherichia coli B2 strains. Appl Environ Microbiol 73, 2373-2377.

Bringer, M. A., Glasser, A. L., Tung, C. H., Meresse, S. \& DarfeuilleMichaud, A. (2006). The Crohn's disease-associated adherent-invasive Escherichia coli strain LF82 replicates in mature phagolysosomes within J774 macrophages. Cell Microbiol 8, 471-484.

Brzuszkiewicz, E., Bruggemann, H., Liesegang, H., Emmerth, M., Olschlager, T., Nagy, G., Albermann, K., Wagner, C., Buchrieser, C. \& other authors (2006). How to become a uropathogen: comparative genomic analysis of extraintestinal pathogenic Escherichia coli strains. Proc Natl Acad Sci U S A 103, 12879-12884.

Chen, S. L., Hung, C. S., Xu, J., Reigstad, C. S., Magrini, V., Sabo, A., Blasiar, D., Bieri, T., Meyer, R. R. \& other authors (2006). Identification of genes subject to positive selection in uropathogenic strains of Escherichia coli: a comparative genomics approach. Proc Natl Acad Sci U S A 103, 5977-5982.

Clermont, O., Bonacorsi, S. \& Bingen, E. (2000). Rapid and simple determination of the Escherichia coli phylogenetic group. Appl Environ Microbiol 66, 4555-4558.

Darfeuille-Michaud, A., Neut, C., Barnich, N., Lederman, E., Di Martino, P., Desreumaux, P., Gambiez, L., Joly, B., Cortot, A. \& Colombel, J. F. (1998). Presence of adherent Escherichia coli strains in ileal mucosa of patients with Crohn's disease. Gastroenterology 115, 1405-1413.

Darfeuille-Michaud, A., Boudeau, J., Bulois, P., Neut, C., Glasser, A. L., Barnich, N., Bringer, M. A., Swidsinski, A., Beaugerie, L. \& 
Colombel, J. F. (2004). High prevalence of adherent-invasive Escherichia coli associated with ileal mucosa in Crohn's disease. Gastroenterology 127, 412-421.

Dobrindt, U., Blum-Oehler, G., Nagy, G., Schneider, G., Johann, A., Gottschalk, G. \& Hacker, J. (2002). Genetic structure and distribution of four pathogenicity islands (PAI $\mathrm{I}_{536}$ to PAI $\mathrm{IV}_{536}$ ) of uropathogenic Escherichia coli strain 536. Infect Immun 70, 6365-6372.

Dobrindt, U., Hochhut, B., Hentschel, U. \& Hacker, J. (2004). Genomic islands in pathogenic and environmental microorganisms. Nat Rev Microbiol 2, 414-424.

Ewers, C., Li, G., Wilking, H., Kiebetaling, S., Alt, K., Antao, E. M., Laturnus, C., Diehl, I., Glodde, S. \& other authors (2007). Avian pathogenic, uropathogenic, and newborn meningitis-causing Escherichia coli: how closely related are they? Int J Med Microbiol 297, 163-176.

Gal-Mor, O. \& Finlay, B. B. (2006). Pathogenicity islands: a molecular toolbox for bacterial virulence. Cell Microbiol 8, 1707-1719.

Greten, F. R., Eckmann, L., Greten, T. F., Park, J. M., Li, Z. W., Egan, L. J., Kagnoff, M. F. \& Karin, M. (2004). IKK $\beta$ links inflammation and tumorigenesis in a mouse model of colitis-associated cancer. Cell 118, 285-296.

Guyer, D. M., Kao, J. S. \& Mobley, H. L. (1998). Genomic analysis of a pathogenicity island in uropathogenic Escherichia coli CFT073: distribution of homologous sequences among isolates from patients with pyelonephritis, cystitis, and catheter-associated bacteriuria and from fecal samples. Infect Immun 66, 4411-4417.

Hejnova, J., Dobrindt, U., Nemcova, R., Rusniok, C., Bomba, A., Frangeul, L., Hacker, J., Glaser, P., Sebo, P. \& Buchrieser, C. (2005). Characterization of the flexible genome complement of the commensal Escherichia coli strain A0 34/86 (O83: K24: H31). Microbiology 151, 385-398.

Hochhut, B., Wilde, C., Balling, G., Middendorf, B., Dobrindt, U., Brzuszkiewicz, E., Gottschalk, G., Carniel, E. \& Hacker, J. (2006). Role of pathogenicity island-associated integrases in the genome plasticity of uropathogenic Escherichia coli strain 536. Mol Microbiol 61, 584-595.

Hope, M. E., Hold, G. L., Kain, R. \& El Omar, E. M. (2005). Sporadic colorectal cancer - role of the commensal microbiota. FEMS Microbiol Lett 244, 1-7.

Houdouin, V., Bonacorsi, S., Bidet, P., Bingen-Bidois, M., Barraud, D. \& Bingen, E. (2006). Phylogenetic background and carriage of pathogenicity island-like domains in relation to antibiotic resistance profiles among Escherichia coli urosepsis isolates. J Antimicrob Chemother 58, 748-751.

Johnson, J. R. \& Stell, A. L. (2000). Extended virulence genotypes of Escherichia coli strains from patients with urosepsis in relation to phylogeny and host compromise. J Infect Dis 181, 261-272.

Johnson, J. R., Brown, J. J. \& Maslow, J. N. (1998). Clonal distribution of the three alleles of the $\mathrm{Gal}(\alpha 1-4) \mathrm{Gal}$-specific adhesin gene papG among Escherichia coli strains from patients with bacteremia. J Infect Dis 177, 651-661.

Johnson, J. R., Scheutz, F., Ulleryd, P., Kuskowski, M. A., O'Bryan, T. T. \& Sandberg, T. (2005). Phylogenetic and pathotypic comparison of concurrent urine and rectal Escherichia coli isolates from men with febrile urinary tract infection. J Clin Microbiol 43, 3895-3900.

Johnson, T. J., Kariyawasam, S., Wannemuehler, Y., Mangiamele, P., Johnson, S. J., Doetkott, C., Skyberg, J. A., Lynne, A. M., Johnson, J. R. \& Nolan, L. K. (2007). The genome sequence of avian pathogenic Escherichia coli strain $\mathrm{O} 1: \mathrm{K} 1: \mathrm{H} 7$ shares strong similarities with human extraintestinal pathogenic E. coli genomes. J Bacteriol 189, 3228-3236.

Kaper, J. B., Nataro, J. P. \& Mobley, H. L. (2004). Pathogenic Escherichia coli. Nat Rev Microbiol 2, 123-140.
Klemm, P. \& Schembri, M. A. (2000). Bacterial adhesins: function and structure. Int J Med Microbiol 290, 27-35.

Kotlowski, R., Bernstein, C. N., Sepehri, S. \& Krause, D. O. (2007). High prevalence of Escherichia coli belonging to the $\mathrm{B} 2+\mathrm{D}$ phylogenetic group in inflammatory bowel disease. Gut 56, 669-675.

Liu, Y., van Kruiningen, H. J., West, A. B., Cartun, R. W., Cortot, A. \& Colombel, J. F. (1995). Immunocytochemical evidence of Listeria, Escherichia coli, and Streptococcus antigens in Crohn's disease. Gastroenterology 108, 1396-1404.

Lloyd, A. L., Rasko, D. A. \& Mobley, H. L. (2007). Defining genomic islands and uropathogen-specific genes in uropathogenic Escherichia coli. J Bacteriol 189, 3532-3546.

Mager, D. L. (2006). Bacteria and cancer: cause, coincidence or cure? A review. J Transl Med 4, 14.

Manson, J. M. \& Gilmore, M. S. (2006). Pathogenicity island integrase cross-talk: a potential new tool for virulence modulation. Mol Microbiol 61, 555-559.

Martin, H. M., Campbell, B. J., Hart, C. A., Mpofu, C., Nayar, M., Singh, R., Englyst, H., Williams, H. F. \& Rhodes, J. M. (2004). Enhanced Escherichia coli adherence and invasion in Crohn's disease and colon cancer. Gastroenterology 127, 80-93.

Meconi, S., Vercellone, A., Levillain, F., Payre, B., AI Saati, T., Capilla, F., Desreumaux, P., Darfeuille-Michaud, A. \& Altare, F. (2007). Adherentinvasive Escherichia coli isolated from Crohn's disease patients induce granulomas in vitro. Cell Microbiol 9, 1252-1261.

Middendorf, B., Hochhut, B., Leipold, K., Dobrindt, U., Blum-Oehler, G. \& Hacker, J. (2004). Instability of pathogenicity islands in uropathogenic Escherichia coli 536. J Bacteriol 186, 3086-3096.

Mylonaki, M., Rayment, N. B., Rampton, D. S., Hudspith, B. N. \& Brostoff, J. (2005). Molecular characterization of rectal mucosaassociated bacterial flora in inflammatory bowel disease. Inflamm Bowel Dis 11, 481-487.

Oelschlaeger, T. A., Dobrindt, U. \& Hacker, J. (2002a). Pathogenicity islands of uropathogenic E. coli and the evolution of virulence. Int $J$ Antimicrob Agents 19, 517-521.

Oelschlaeger, T. A., Dobrindt, U. \& Hacker, J. (2002b). Virulence factors of uropathogens. Curr Opin Urol 12, 33-38.

Perna, N. T., Plunkett, G., III, Burland, V., Mau, B., Glasner, J. D., Rose, D. J., Mayhew, G. F., Evans, P. S., Gregor, J. \& other authors (2001). Genome sequence of enterohaemorrhagic Escherichia coli O157: H7. Nature 409, 529-533.

Rasko, D. A., Phillips, J. A., Li, X. \& Mobley, H. L. (2001). Identification of DNA sequences from a second pathogenicity island of uropathogenic Escherichia coli CFT073: probes specific for uropathogenic populations. J Infect Dis 184, 1041-1049.

Rhodes, J. M. \& Campbell, B. J. (2002). Inflammation and colorectal cancer: IBD-associated and sporadic cancer compared. Trends $\mathrm{Mol}$ Med 8, 10-16.

Rodriguez-Siek, K. E., Giddings, C. W., Doetkott, C., Johnson, T. J., Fakhr, M. K. \& Nolan, L. K. (2005). Comparison of Escherichia coli isolates implicated in human urinary tract infection and avian colibacillosis. Microbiology 151, 2097-2110.

Rolhion, N., Barnich, N., Claret, L. \& Darfeuille-Michaud, A. (2005). Strong decrease in invasive ability and outer membrane vesicle release in Crohn's disease-associated adherent-invasive Escherichia coli strain LF82 with the $y f g L$ gene deleted. J Bacteriol 187, 2286-2296.

Rolhion, N., Carvalho, F. A. \& Darfeuille-Michaud, A. (2007). OmpC and the $\sigma^{\mathrm{E}}$ regulatory pathway are involved in adhesion and invasion of the Crohn's disease-associated Escherichia coli strain LF82. Mol Microbiol 63, 1684-1700. 
Ryan, P., Kelly, R. G., Lee, G., Collins, J. K., O'Sullivan, G. C., O'Connell, J. \& Shanahan, F. (2004). Bacterial DNA within granulomas of patients with Crohn's disease - detection by laser capture microdissection and PCR. Am J Gastroenterol 99, 1539-1543.

Sabaté, M., Moreno, E., Perez, T., Andreu, A. \& Prats, G. (2006). Pathogenicity island markers in commensal and uropathogenic Escherichia coli isolates. Clin Microbiol Infect 12, 880-886.

Schmidt, H. \& Hensel, M. (2004). Pathogenicity islands in bacterial pathogenesis. Clin Microbiol Rev 17, 14-56.

Schubert, S., Rakin, A. \& Heesemann, J. (2004). The Yersinia highpathogenicity island (HPI): evolutionary and functional aspects. Int $J$ Med Microbiol 294, 83-94.

Simpson, K. W., Dogan, B., Rishniw, M., Goldstein, R. E., Klaessig, S., McDonough, P. L., German, A. J., Yates, R. M., Russell, D. G. \& other authors (2006). Adherent and invasive Escherichia coli is associated with granulomatous colitis in boxer dogs. Infect Immun 74, 4778-4792.

Swidsinski, A., Khilkin, M., Kerjaschki, D., Schreiber, S., Ortner, M., Weber, J. \& Lochs, H. (1998). Association between intraepithelial Escherichia coli and colorectal cancer. Gastroenterology 115, 281-286.
Swidsinski, A., Ladhoff, A., Pernthaler, A., Swidsinski, S., LoeningBaucke, V., Ortner, M., Weber, J., Hoffmann, U., Schreiber, S. \& other authors (2002). Mucosal flora in inflammatory bowel disease. Gastroenterology 122, 44-54.

Welch, R. A., Burland, V., Plunkett, G., III, Redford, P., Roesch, P., Rasko, D., Buckles, E. L., Liou, S. R., Boutin, A. \& other authors (2002). Extensive mosaic structure revealed by the complete genome sequence of uropathogenic Escherichia coli. Proc Natl Acad Sci U S A 99, 17020-17024.

Whitfield, C. \& Roberts, I. S. (1999). Structure, assembly and regulation of expression of capsules in Escherichia coli. Mol Microbiol 31, 1307-1319.

Wullt, B., Bergsten, G., Connell, H., Rollano, P., Gebretsadik, N., Hull, R. \& Svanborg, C. (2000). P fimbriae enhance the early establishment of Escherichia coli in the human urinary tract. Mol Microbiol 38, 456-464.

Wullt, B., Bergsten, G., Samuelsson, M. \& Svanborg, C. (2002). The role of P fimbriae for Escherichia coli establishment and mucosal inflammation in the human urinary tract. Int J Antimicrob Agents 19, 522-538.

Edited by: D. L. Gally 